\title{
Social inequality, human development and fertility pattern in Brazil, 2000-2010
}

\section{Gabrielle Braga Carreira 1}

https://orcid.org/0000-0002-6691-0942

Viviane Gomes Parreira Dutra 2

https://orcid.org/0000-0001-6939-742X

José Henrique Costa Monteiro da Silva 3

https://orcid.org/0000-0001-9674-3041

Raphael Mendonça Guimarães 4

https://orcid.org/0000-0003-1225-6719

1 Secretaria Municipal de Saúde do Rio de Janeiro. Rio de Janeiro, RJ, Brasil.

2 Núcleo de Avaliação Tecnológica em Saúde. Ministério da Saúde. Rio de Janeiro, RJ, Brasil.

3 Núcleo de Estudos de População. Universidade Estadual de Campinas. Campinas, SP, Brasil.

4 Escola Politécnica de Saúde Joaquim Venâncio.Fundação Oswaldo Cruz. Avenida Brasil, 4365. Rio de Janeiro, RJ, Brasil. CEP 21.041-360.

E-mail: raphael.guimaraes@fiocruz.br

\begin{abstract}
Objectives: to analyze the fertility pattern in Brazil and its relationship with human development in the Brazilian federation units in 2000 and 2010.

Methods: this is an ecological study whose unit of analysis was the Brazilian Federative Units in the period of 2000 and 2010. The fertility was assessed considering the social (HDI), inequality, (Gini, Theil and Income Ratio) and fertility indicators (fertility rate and mean age of fertility).

Results: Brazil has been experiencing a rapid fertility transition. The pattern of fertility curves changed in all Federative Units between 2000 and 2010, with a reduction in cusp size and postponement of fecundity. This change was more evident among the Federative Units with better development and lower inequality. The correlation between social and fertility indicators lost strength in the period, corroborating the transition hypothesis.

Conclusions: there is a direct relation between the fecundity and inequality indicators, and inversing human development. Changes should be taken in consideration in the age structure of the population, as well as inequality indicators, for better planning in public policies for public health.
\end{abstract}

Key words Fertility, Demography, Human development indicators, Fertility postponement, Public policies 


\section{Introduction}

During the twentieth century, the global population underwent unprecedented increases in the economic and social development, which coincided with substantial declines in human fertility and population growth rates. The history of the demographic and cultural behavior of certain populations has taken on a more diversified picture, through local and regional variations, gaining recognition of new patterns in an important way. ${ }^{1}$

There is unequivocally a "fertility revolution" process, which is embedded in the inherent processes to the modernization of the society in general: economic and productive modernization (new productive models, transportation, etc.), demographic modernization (new fertility regimes, mortality and migration influenced by the advances in public health) and individual modernization (greater openness to individual freedoms and the pursuit of individual and child self-fulfillment). ${ }^{2}$ These phenomena have led to a reduction in fertility from six to two children per woman, representing a gain in individual female liberties in terms of having more time for their own self. 3 That is, the modernization of reproductive behavior is based on the autonomy of the couple to decide their own reproductive behavior, overcoming the biological and social determinants (customs) that previously were placed as determinants of the size of the family.2,4

The negative association of fertility with economic and social development, often assessed through the Human Development Index (HDI), becoming one of the most solidly established theories, and has presented some empirical regularity in the data, thereby gaining credibility in the social sciences. 5 As a result of this close connection between development and a decline in fertility, more than half of the global population lives in regions with below-replacement fertility rates (fewer than 2.1 children per woman of childbearing age). ${ }^{6}$

Particularly, in several countries including Brazil, the factors that are negatively correlated with low fertility during the fertility transition period are mainly income and educational level. Although it is observed that the fertility rate becomes more and more homogeneous among the different socioeconomic levels of social groups, between the extremes of these groups, rates still present a significant difference. ${ }^{7}$ In this case, it is evident that the formulation of policies, mainly thinking about their effectiveness, depends on more careful analysis of the scenarios which weigh the inequality of income distribution and access to schooling and health services. Thus, it is necessary to evaluate the new scenario of the demographic transition, with possible postponement of age at first gestation. Therefore, the objective of the present study is to analyze the fertility pattern in Brazil and its relationship with human development in the Federative units in Brazil between 2000 and 2010 .

\section{Methods}

This is an ecological study whose unit of analysis was the Brazilian Federative units in the period from 2000 to 2010 . Fertility was evaluated considering the following indicators:

\section{Social indicators}

\section{a) Gini index}

This measures the degree of inequality in the distribution of individuals according to per capita household income. Its amplitude goes from zero, when there is no inequality, to 1 , when the inequality is at a maximum;

\section{b) Theil's $L$ index}

This measures inequality in the distribution of individuals according to per capita household income, excluding those with zero per capita household income. It is calculated through the logarithm of the ratio between the arithmetic and geometric means of household income per capita of individuals, ranging from zero - when there is no income inequality, and infinite - when inequality tends to the maximum;

\section{c) $10 \%$ of the richest ratio $/ 40 \%$ of the poorest}

This evaluates the degree of inequality in the distribution of individuals according to per capita household income. It compares the average per capita income of individuals belonging to the richest quintile and the two poorest quintiles;

\section{d) Human Development Index (HDI)}

This is a multidimensional index that evaluates the development conditions of the sites by calculating the geometric mean of the sub-indices of the dimensions Income, Education and Longevity with equal weights.

i) HDI Income: obtained from the "income per capita" indicator

ii) HDI Longevity: obtained from the life expectancy at birth indicator

iii) HDI Education: a synthetic sub-index, obtained by means of the geometric mean of the 
frequency of children and young people in school with a weight of two-thirds, and the adult population in schooling with a weight of one-third.

\section{Fertility indicators}

\section{Correction in the volume of births}

For methodological and operational reasons, the longitudinal analyses with cohort data are a little uncommon. This is because not all the necessary data are always available. Additionally, there may be a problem with the quality of the data available. To overcome these difficulties, indirect methods are used to calculate some statistics. It is important to note that fertility time effects are defined as period level changes and do not necessarily reflect changes in the total fertility level of the cohorts. Changes in the ages in which women give birth to their children show that fertility measured at a given time (period) may not be a good representation of the these women's final fertility. In this sense, the Gompertz synthetic relational method was used, considering the period of the study, thus better simulating the behavior of the cohorts.

The Relational Gompertz Synthetic Model is an extension of the Gompertz Relational Model to estimate the fertility of the interval period between two surveys (in the present study, from the 2000 and 2010 Demographic Censuses), capturing possible changes in fertility. ${ }^{8}$ Even as the Gompertz relational model, the synthetic model uses data on parturition and live births in the last 12 months to adjust the fertility observed in the period from the mean parturition and the specific fertility rates of quinquennial age groups of women. The adjustment is made from established relationships between observed fertility for the period and a standard fertility distribution. The model basically estimates two parameters that adjust the standard curve to the observed behavior: one for level adjustment and another for curve adjustment.

From the volume of births duly corrected, the following indicators of fertility were elaborated:

\section{a) General Fertility Rate}

It is the ratio between the number of live births and the female population within the reproductive period (fertile age). The fertile age of the female population is used to be considered between 15 and 49 years of age.

$$
\mathrm{TFG}_{\mathrm{j}}=\frac{\mathrm{B}_{\mathrm{j}}}{{ }_{35 \mathrm{M}_{15, \mathrm{j}}}}
$$

Where ${ }_{35} \mathrm{M}_{15, j}$ is the number of women between 15 and 49 years old at year $j$, and $B_{j}$ is the number of births at year $\mathrm{j}$.

This indicator depends on the greater or less intensity with which women have children at each age, and the age distribution in the female population within the range of fertile age. In this way, it is recommended to use it for comparison purposes only in situations where the age structure is similar.

\section{b) Specific fertility rate (TEF)}

This is the ratio between the number of live births to mothers in a certain age group and the number of women in the same age group.

$$
{ }_{n} \mathrm{TEF}_{\mathrm{x}, \mathrm{j}}=\frac{{ }_{n} \mathrm{~B}_{\mathrm{x}, \mathrm{j}}}{{ }_{n} \mathrm{M}_{\mathrm{x}, \mathrm{j}}}
$$

Where ${ }_{35} \mathrm{M}_{15, \mathrm{f}, \mathrm{j}}$ is the number of women at age between $x$ and $x+n$ at year $j$, e and $B_{j}$ is the number of births from women at age between $\mathrm{x}$ and $\mathrm{x}+\mathrm{n}$ at year $\mathrm{j}$.

It is a more refined indicator, since it specifies the fertility in the age groups. Usually, it is calculated with quinquennial age range between 15 and 49 years old.

\section{c) Total fertility rate}

This is the mean number of children a woman would have at the end of the reproductive period (current fertility). The total fertility rate (TFR) depends on the TEF set, since it is calculated from its summing, considering the age range:

$$
\mathrm{TFT}_{\mathrm{j}}=\mathrm{n} * \sum_{\mathrm{x}} \mathrm{n}^{\mathrm{TEF}} \mathrm{F}_{\mathrm{x}}
$$

Where ${ }_{n} T^{2} F_{x}$ represents the (TEF) in the range age of $x$ to $x+n$.

As TFR is not influenced by the age distribution of women in the reference population, the TFRs from different populations can be used to compare fertility levels.

\section{d) Mean age of fertility}

The mean age of fertility is the ratio between the sum of the specific mean and the fertility rates in each age group and the sum of the specific fertility rates:

$$
\operatorname{IMF}=\frac{\sum\left({ }_{n} \mathrm{TEF}_{\mathrm{x}, \mathrm{j}} * \bar{x}\right)}{\sum_{n} \mathrm{TEF}_{\mathrm{x}, \mathrm{j}}}
$$

This calculation as it is based on the specific 
fertility rates it allows neutralization of the distortions provoked by the alterations in the female population's age structure by facilitating comparison between different Federation units.

Initially, the fertility indicators were described in 2000 and 2010, in each Brazilian federative unit, through means and deviations. After that, the fertility curves were elaborated for the two years, by the federative unit.

The relationship between TFR and mean fertility age (MFA) was explored in an attempt to observe a change in the period analyzed. Finally, tests were performed to verify simple association between the variables of fertility and social indicators, using the Spearman correlation coefficient. A correlation of $p$ value less than 0.05 was considered statistically significant.

The present study used secondary data from public databases, without any type of individual identification. Thus, in accordance with resolution $466 / 2012$, the project is exempt from submission to the Research Ethics Committee.

\section{Results}

Brazil has been experiencing a rapid transition in fertility. This difference is evident when we observe the variability of the synthetic indicators of fertility (TFR and MFA) in 2000 and 2010 (Table 1). In addition to a reduction in TFR and an increase in MFA, there was a reduction in the variability of both, pointing to a convergence around the mean. It is important to note that the variation of the indicators shows, in general, an improvement in the social indicators, as well as ratifying the transition in fertility as mentioned above (Figure 1).

This theory seems to be consistent with the general analysis of the Federative Unit (FU) fertility curves (Figure 2). In general, there is a postponement of fertility behavior regardless to the location analyzed. However, there is a difference in the level, either the difference is in the 2000 curve or in the speed in which the phenomenon occurs, which results in the differences observed between the FU when compared to the 2000 and 2010 curves. With the changes, besides the different level, there is evidence in the alteration in the shape of the fertility curve. It is noticed that the higher TEF are concentrated in the younger age groups (15 to 19 and 20 to 24 years old). There is also a continuous reduction in the adolescents' TEF in 2000, as well as an increase in the relative participation of women in these age groups 25 to 29 and 30 to 34. Finally, in some areas, the occurrence of a less obvious cusp was observed. This pattern is more noticeable among more deve- loped units, such as those in the South and the Federal District.

Thus, there are alterations in both the level and structure of the fertility curves (time and quantum effect). Our results tend to support the growing hypothesis of age heterogeneity at first birth in several countries and regions. In particular, Southeast and South axis States show the highest level of dispersion in the onset of fertility postponement, resulting in a lower TFR.

The results for FU corroborate the hypothesis that the fertility decline seems to be more influenced by the evident reduction in births from the second (20 to 24 years) and third orders (25 to 29 years), and a slight increase in the larger orders. Thus, although there was a reduction in the fertility rates, this change is less significant in the MFA (Figure 3).

When the observed fertility index is expressed, the TFR for the values of the main social indicators evaluated (Gini index, Theil's L index, income ratio and HDI), it is observed that there is a difference between the years 2000 and 2010. The analysis suggests that in 2000 , the relation between these indicators would be more evident, and that it had weakened by 2010 . In fact, when the correlation coefficients were observed (Table 2), most correlations which were strong and significant in 2000 became weaker and no longer were significant in 2010. The direct relation between the inequality and TFR indicators show an inverse correlation between human development and TFR. However, when this correlation was shown to be significant, it was only for TFR, and not for MFA.

\section{Discussion}

During the demographic transition, the different periods of declining fertility and mortality in different parts of the world have promoted global demographic instability. ${ }^{9}$ According to the latest projections from the United Nations, by the year 2100 , the net migration to each state of the world will be zero, the number of children per woman everywhere (except in a number of countries) will be between 1.8 and 2.2, and life expectancy will be between 70 and 95 years (a much narrower difference than nowadays). ${ }^{10}$

Some Latin American countries have experienced the beginning of the postponement transition since 2000. Among them, Argentina, Brazil, Chile and Uruguay - all belonging to the South Cone appear to be at the forefront of this change. 11 Due to the persistence of high adolescent fertility rates in Latin American countries, 12,13 the partial change to late motherhood explains, in some terms, a greater 
Social and Fertility Indicators according to the Federation unit. Brazil, 2000 and 2010.

\begin{tabular}{|c|c|c|c|c|c|c|c|c|c|c|c|c|}
\hline \multirow{3}{*}{ FU } & \multicolumn{8}{|c|}{ Social Indicators } & \multicolumn{4}{|c|}{ Reproductive Indicators } \\
\hline & \multicolumn{2}{|c|}{ 10/40 Ratio } & \multicolumn{2}{|c|}{$\begin{array}{l}\text { Theil - L Index } \\
2000\end{array}$} & \multicolumn{2}{|c|}{$\begin{array}{l}\text { Gini Index } \\
2000\end{array}$} & \multicolumn{2}{|c|}{ HDI } & \multicolumn{2}{|c|}{ TFR } & \multicolumn{2}{|c|}{ MFA } \\
\hline & 2000 & 2010 & 2000 & 2010 & 2000 & 2010 & 2000 & 2010 & 2000 & 2010 & 2000 & 2010 \\
\hline Rondônia & 23.92 & 17.86 & 0.64 & 0.56 & 0.60 & 0.56 & 0.537 & 0.69 & 2.75 & 2.16 & 24.64 & 25.64 \\
\hline Acre & 32.17 & 29.35 & 0.72 & 0.73 & 0.64 & 0.63 & 0.517 & 0.663 & 3.42 & 2.95 & 25.74 & 26.40 \\
\hline Amazonas & 39.77 & 33.55 & 0.78 & 0.8 & 0.67 & 0.65 & 0.515 & 0.674 & 3.45 & 2.59 & 26.02 & 26.16 \\
\hline Roraima & 26.95 & 30.89 & 0.64 & 0.75 & 0.61 & 0.63 & 0.598 & 0.707 & 3.22 & 2.41 & 25.68 & 26.16 \\
\hline Pará & 30.56 & 26.25 & 0.74 & 0.70 & 0.65 & 0.62 & 0.518 & 0.646 & 3.15 & 2.50 & 25.60 & 25.49 \\
\hline Amapá & 27.79 & 24.07 & 0.70 & 0.68 & 0.62 & 0.60 & 0.577 & 0.708 & 3.63 & 2.48 & 26.09 & 26.24 \\
\hline Tocantins & 31.68 & 23.33 & 0.73 & 0.68 & 0.65 & 0.60 & 0.525 & 0.699 & 2.95 & 2.41 & 24.91 & 25.70 \\
\hline Maranhão & 33.43 & 28.61 & 0.75 & 0.74 & 0.65 & 0.62 & 0.476 & 0.639 & 3.20 & 2.56 & 25.79 & 25.62 \\
\hline Piauí & 33.69 & 26.43 & 0.79 & 0.73 & 0.65 & 0.61 & 0.484 & 0.646 & 2.67 & 1.99 & 25.77 & 25.98 \\
\hline Ceará & 36.33 & 24.97 & 0.81 & 0.72 & 0.67 & 0.61 & 0.541 & 0.682 & 2.84 & 1.99 & 27.03 & 27.06 \\
\hline Rio Grande do Norte & 30.83 & 22.99 & 0.73 & 0.68 & 0.64 & 0.60 & 0.552 & 0.684 & 2.54 & 1.98 & 26.22 & 26.71 \\
\hline Paraíba & 28.95 & 24.17 & 0.73 & 0.70 & 0.63 & 0.61 & 0.506 & 0.658 & 2.54 & 1.95 & 26.39 & 26.61 \\
\hline Pernambuco & 33.76 & 26.63 & 0.79 & 0.74 & 0.66 & 0.62 & 0.544 & 0.673 & 2.48 & 1.92 & 26.01 & 26.27 \\
\hline Alagoas & 38.76 & 27.17 & 0.82 & 0.75 & 0.68 & 0.63 & 0.471 & 0.631 & 3.14 & 2.22 & 26.44 & 26.07 \\
\hline Sergipe & 30.93 & 25.71 & 0.76 & 0.72 & 0.65 & 0.62 & 0.518 & 0.665 & 2.74 & 1.95 & 26.70 & 26.88 \\
\hline Bahia & 33.24 & 25.98 & 0.77 & 0.73 & 0.66 & 0.62 & 0.512 & 0.66 & 2.50 & 2.05 & 26.42 & 26.66 \\
\hline Minas Gerais & 24.03 & 17.26 & 0.67 & 0.56 & 0.61 & 0.56 & 0.624 & 0.731 & 2.23 & 1.79 & 26.63 & 27.33 \\
\hline Espírito Santo & 22.65 & 17.74 & 0.65 & 0.56 & 0.60 & 0.56 & 0.640 & 0.740 & 2.16 & 1.80 & 25.94 & 26.76 \\
\hline Rio de Janeiro & 23.18 & 21.19 & 0.67 & 0.64 & 0.60 & 0.59 & 0.664 & 0.761 & 2.06 & 1.68 & 26.20 & 26.81 \\
\hline São Paulo & 20.10 & 17.60 & 0.61 & 0.57 & 0.58 & 0.56 & 0.702 & 0.783 & 2.05 & 1.66 & 26.49 & 27.32 \\
\hline Paraná & 22.43 & 15.23 & 0.65 & 0.51 & 0.60 & 0.53 & 0.650 & 0.749 & 2.30 & 1.86 & 26.24 & 26.90 \\
\hline Santa Catarina & 17.51 & 11.63 & 0.56 & 0.42 & 0.56 & 0.49 & 0.674 & 0.774 & 2.23 & 1.71 & 26.61 & 27.31 \\
\hline Rio Grande do Sul & 20.30 & 15.64 & 0.62 & 0.53 & 0.58 & 0.54 & 0.664 & 0.746 & 2.16 & 1.76 & 27.05 & 27.71 \\
\hline Mato Grosso do Sul & 24.48 & 17.55 & 0.69 & 0.57 & 0.62 & 0.56 & 0.613 & 0.729 & 2.50 & 2.08 & 25.21 & 26.11 \\
\hline Mato Grosso & 24.75 & 16.79 & 0.68 & 0.54 & 0.62 & 0.55 & 0.601 & 0.725 & 2.42 & 2.04 & 24.67 & 25.84 \\
\hline Goiás & 22.55 & 16.27 & 0.65 & 0.53 & 0.6 & 0.55 & 0.615 & 0.735 & 2.23 & 1.87 & 24.81 & 26.18 \\
\hline Distrito Federal & 30.96 & 28.23 & 0.79 & 0.76 & 0.63 & 0.63 & 0.725 & 0.824 & 1.96 & 1.75 & 26.54 & 27.78 \\
\hline Total & 30.31 & 22.78 & 0.76 & 0.68 & 0.64 & 0.60 & 0.612 & 0.727 & 2.37 & 1.89 & 26.25 & 26.75 \\
\hline
\end{tabular}

10/40 Ratio = Average per capita income ratio of the richest $10 \%$ and the poorest $40 \%$; HDI = Human Development Index; TFR = Total Fertility Rate; MFA = Mean Fertility Age. Source: DATASUS, 2018; IBGE 2018. 
10/40 Ratio

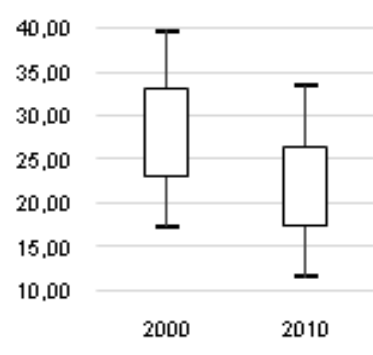

Theil-L

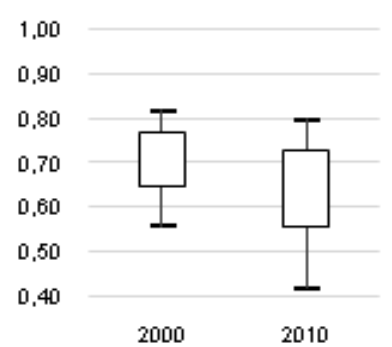

Gini

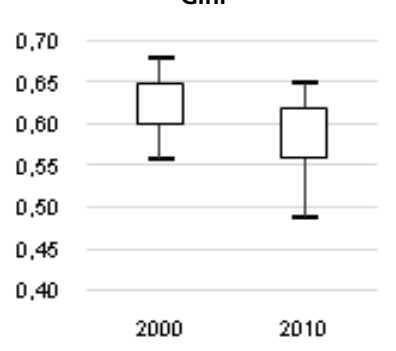

10/40 Ratio

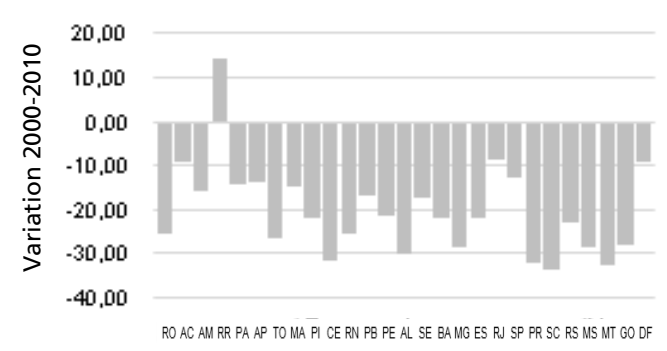

Theil-L

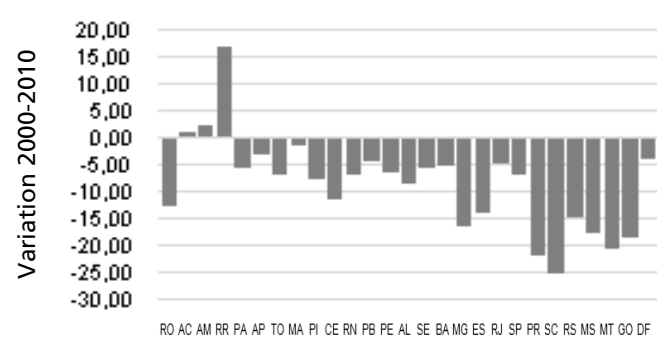

$\operatorname{Gin}$

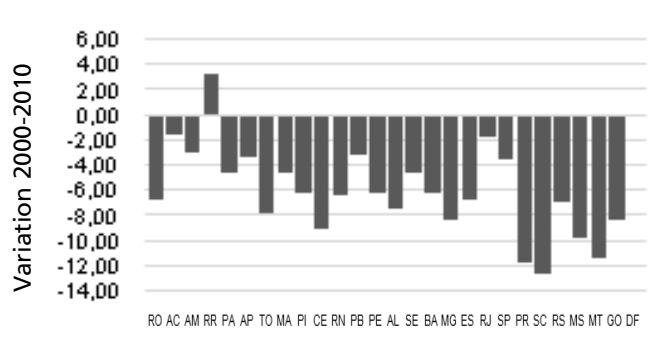

HDI

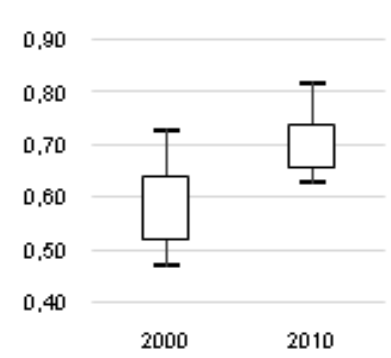

TFR

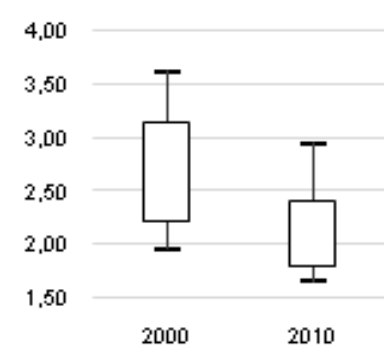

MFA

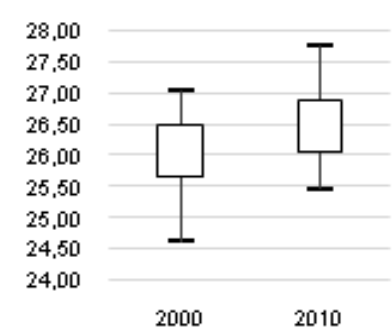

HDI

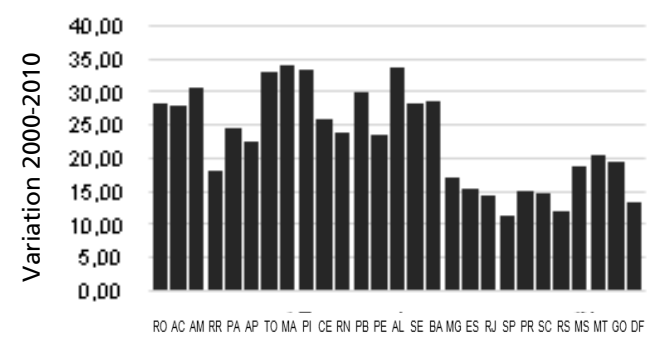

TFR

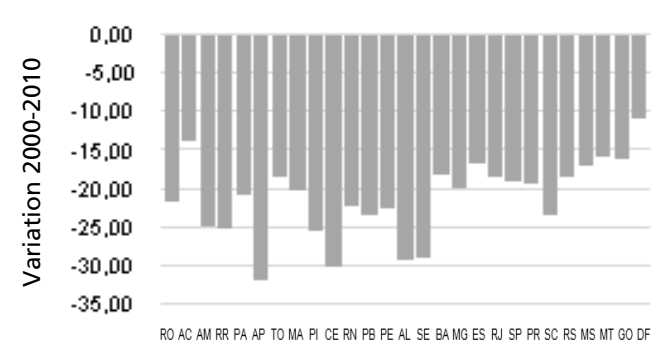

MFA

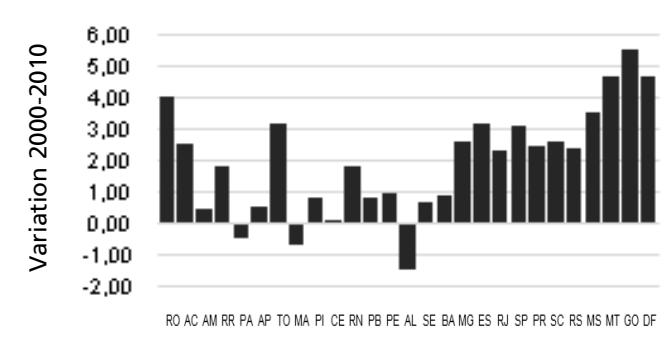

HDI = Human Development Index; TFR = Total Fertility Rate; MFA = Mean Fertility Age Fonte: DATASUS, 2018 
Figure 2

Fertility pattern according to the Federation Unit. Brazil, 2000 and 2010.

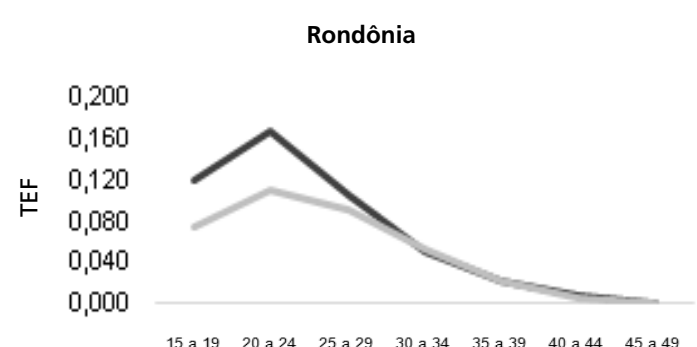

Age

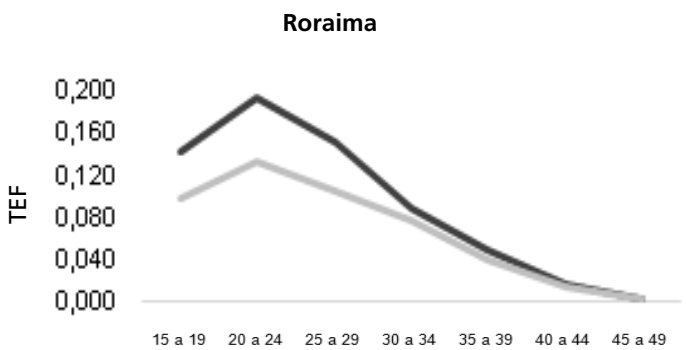

Age

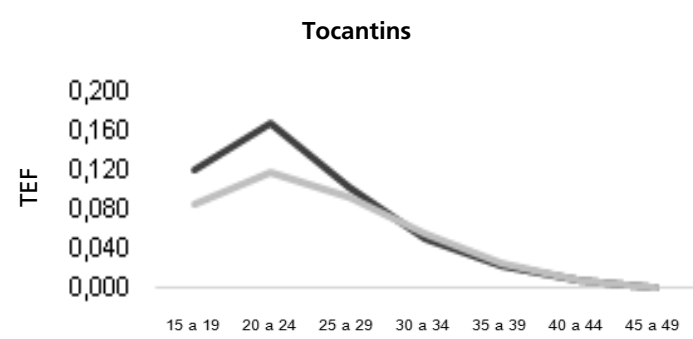

Age

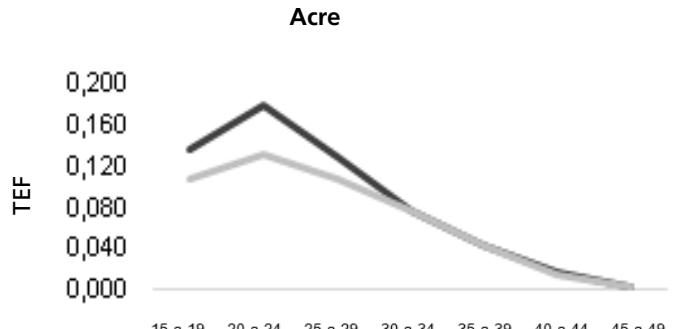

Age

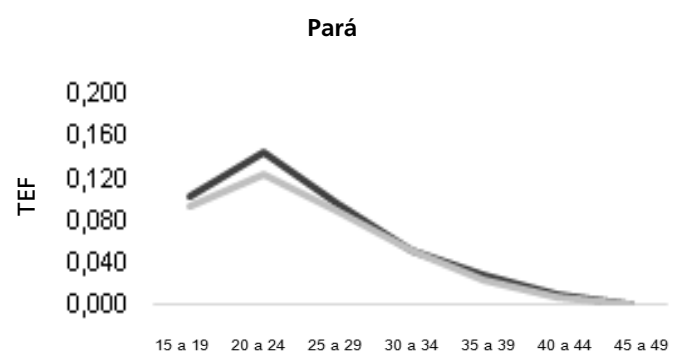

Age

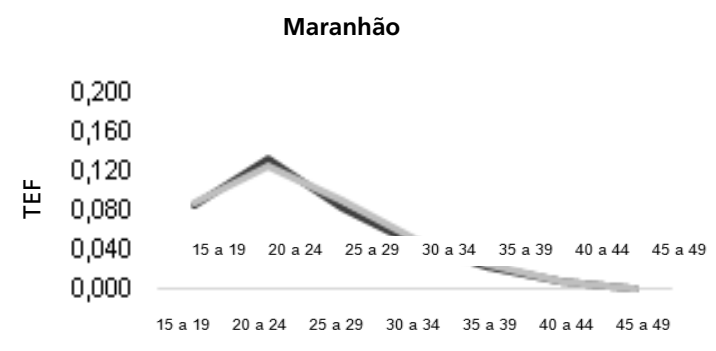

Age

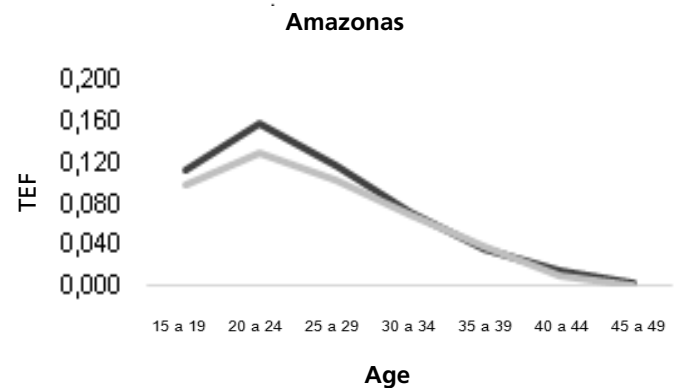

Age

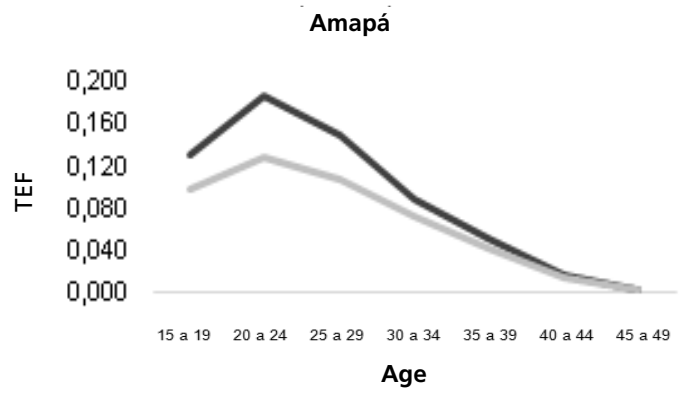

Piauí

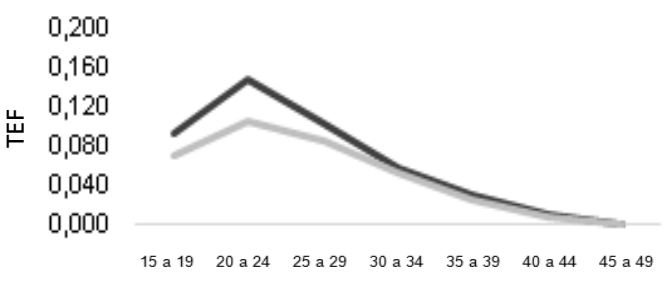

Age 
Fertility pattern according to the Federation Unit. Brazil, 2000 and 2010.

Ceará

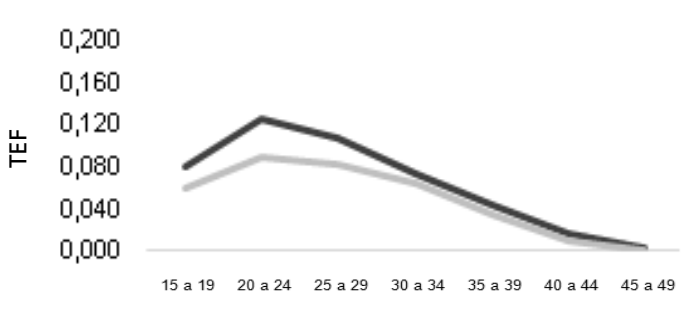

Age

Pernambuco

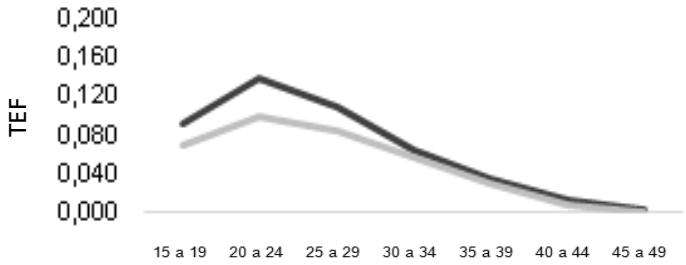

Age

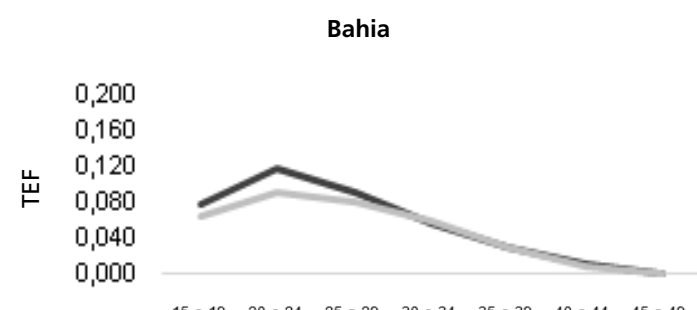

Age
Rio Grande do Norte

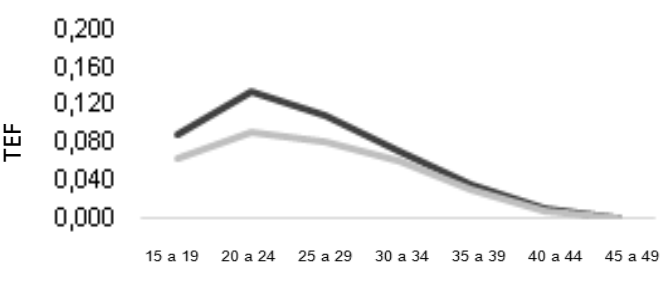

Age

Alagoas

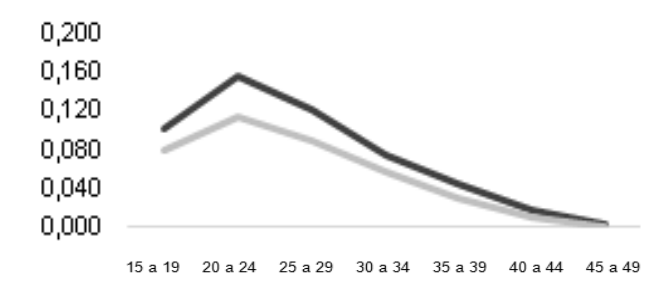

Age

Minas Gerais

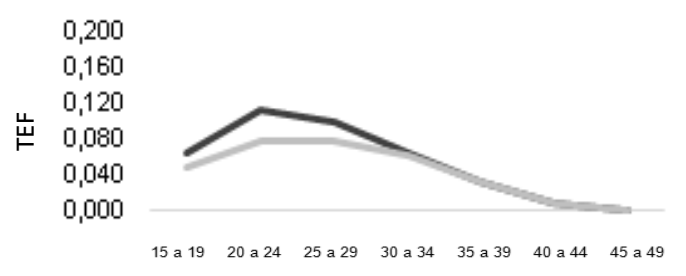

Age
Paraíba

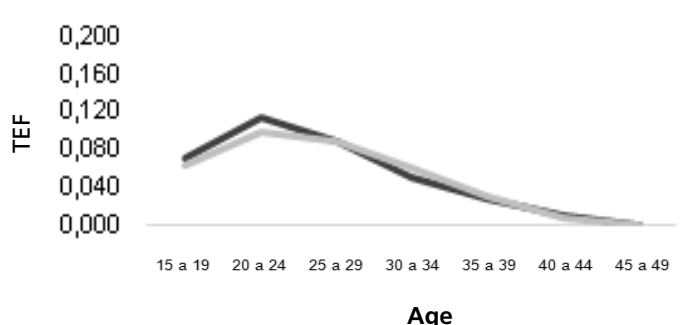

Sergipe

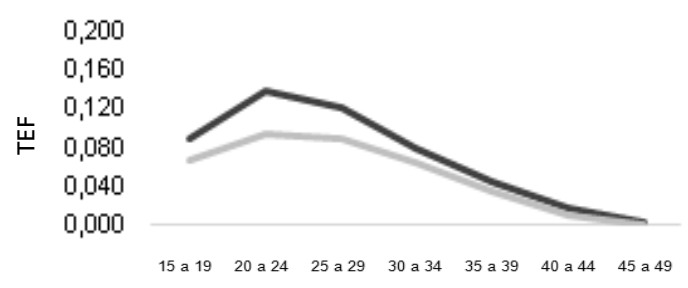

Age

Espírito Santo

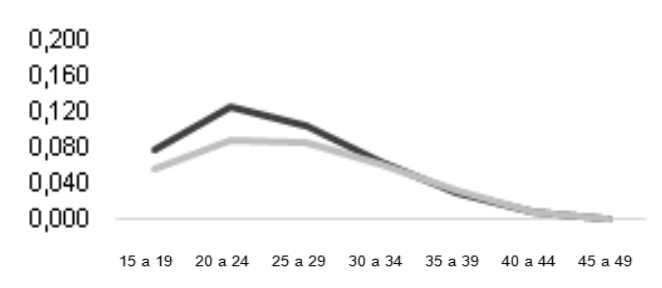

Age

Subtitle:

2000

$T E F=$ specific fertility rate. Source: DATASUS, 2018 
Fertility pattern according to the Federation Unit. Brazil, 2000 and 2010

Rio de Janeiro

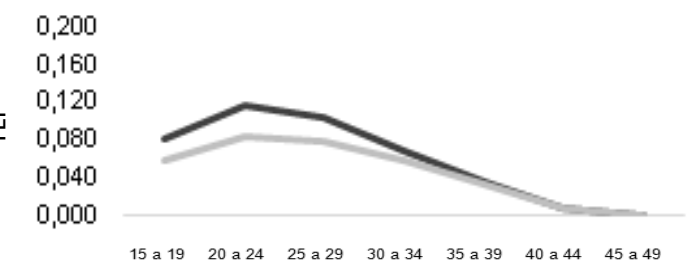

Age

Santa Catarina

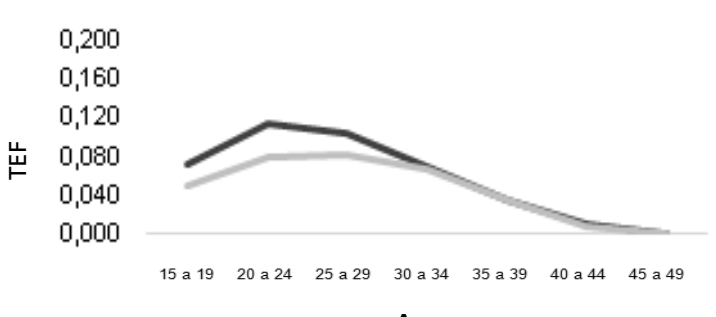

Age

Mato Grosso

0,200

0,160

$\begin{array}{ll}\stackrel{u}{\rightleftarrows} \quad 0,120 \\ \vdash\end{array} \quad 0,080$

0,080

0,000

$\begin{array}{lllllll}15 \text { a } 19 & 20 \text { a } 24 & 25 \text { a } 29 & 30 \text { a } 34 & 35 \text { a } 39 & 40 \text { a } 44 & 45 \text { a } 49\end{array}$

Age
São Paulo

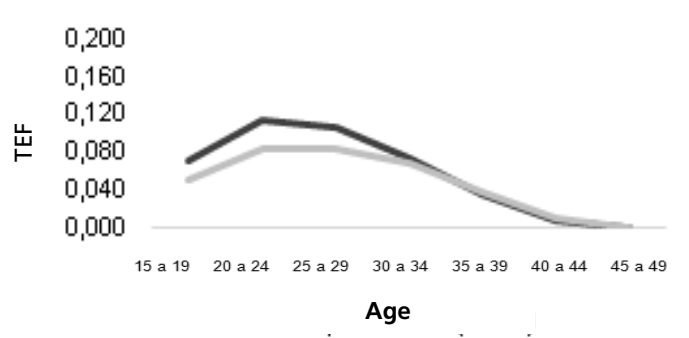

Rio Grande do Sul

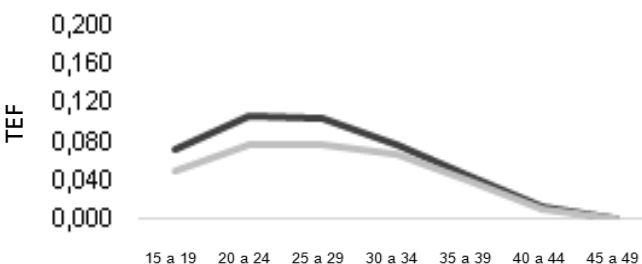

Age

Goiás

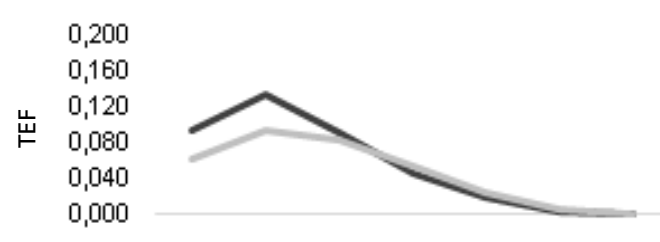

Age
Paraná

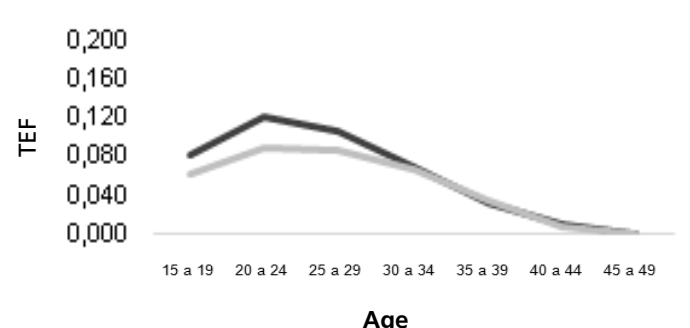

Mato Grosso do Sul

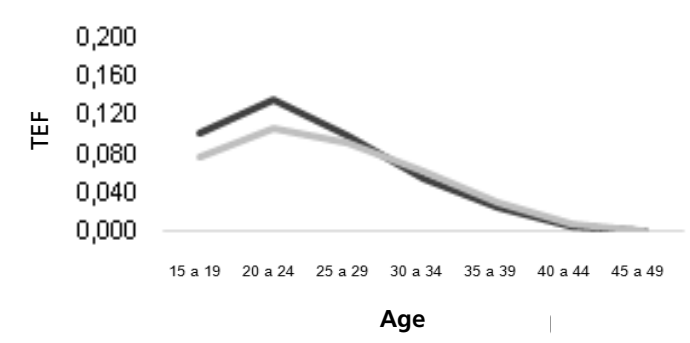

Distrito Federal

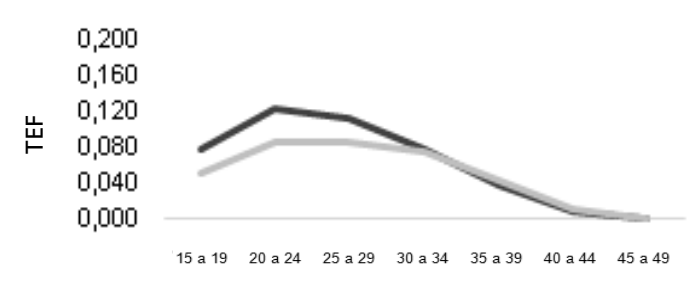

Age

Subtitle: 2000

TEF = specific fertility rate. Source: DATASUS, 2018 

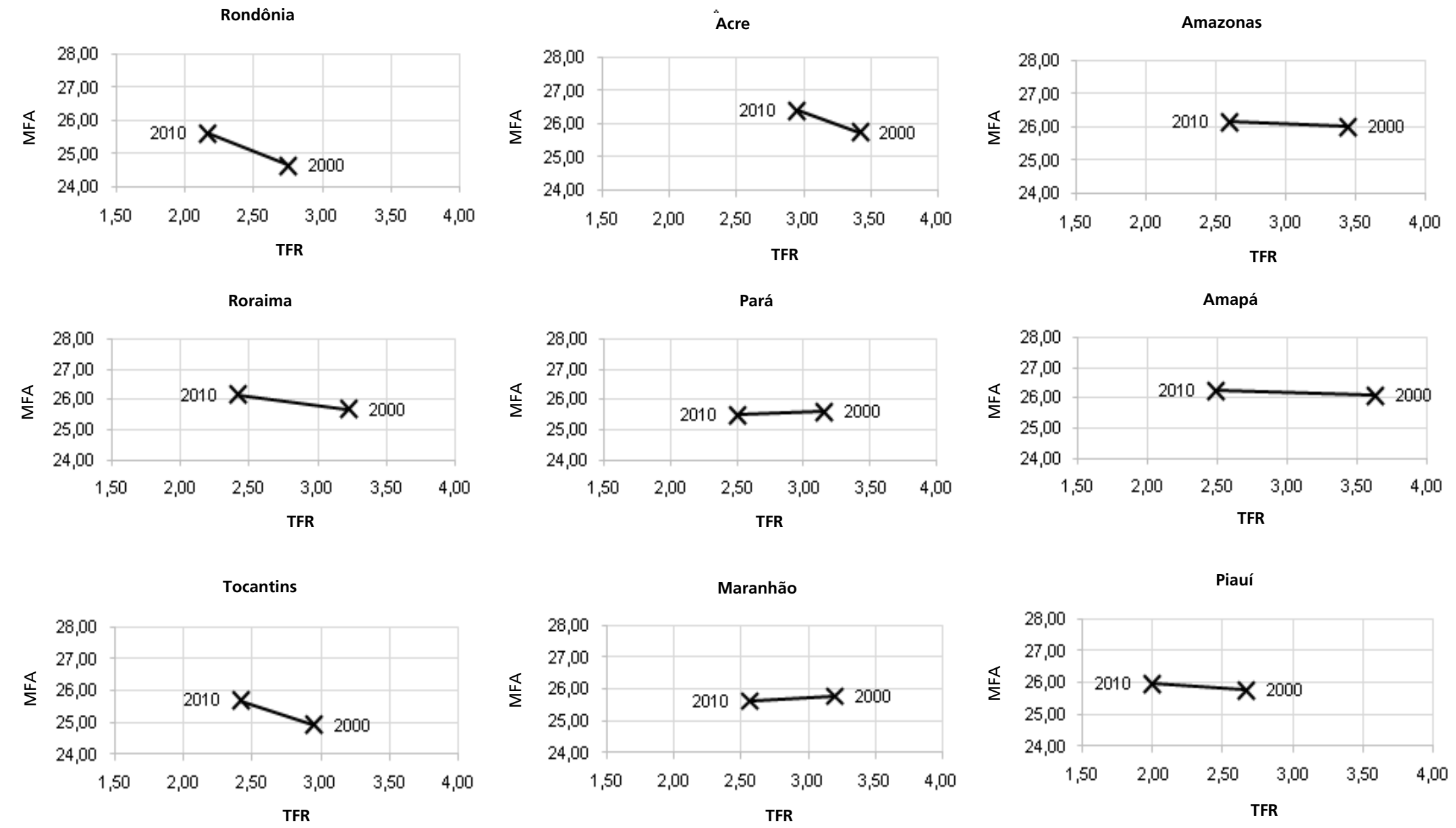
Relation between the Total Fertility Rate and Mean Fertility Age according to the Federation Unit. Brazil, 2000 and 2010.

Ceará

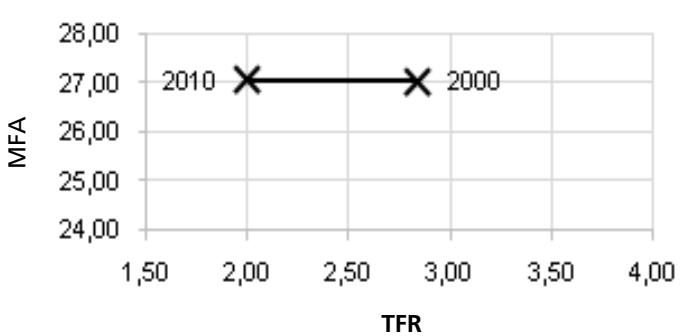

Pernambuco

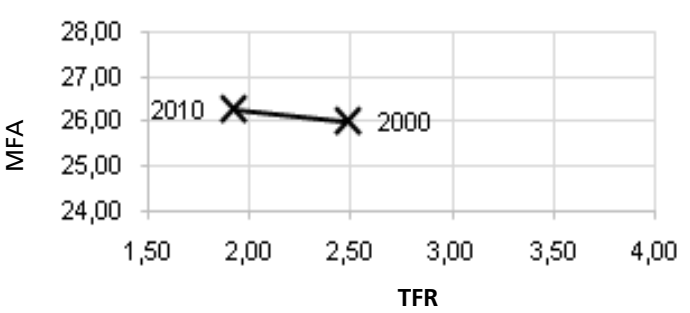

Bahia

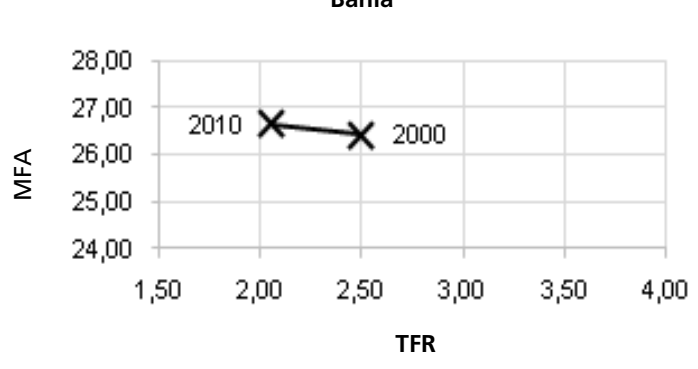

Rio Grande do Norte

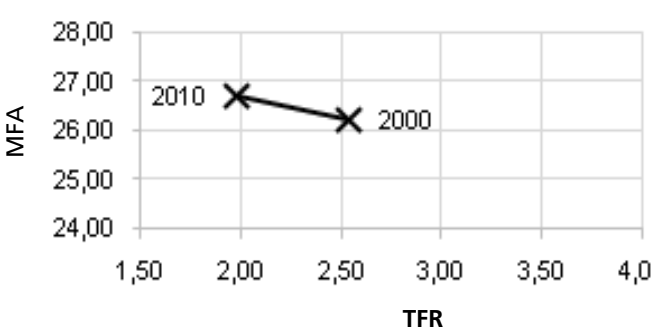

Alagoas

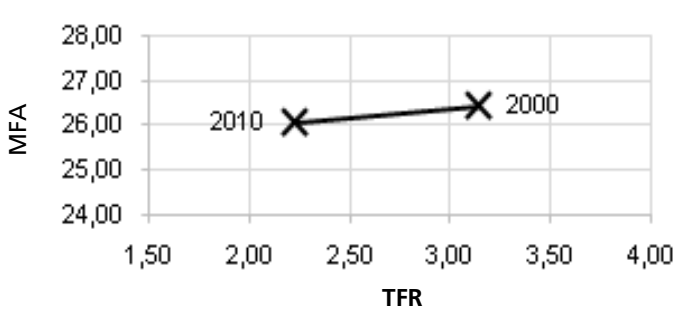

Minas Gerais

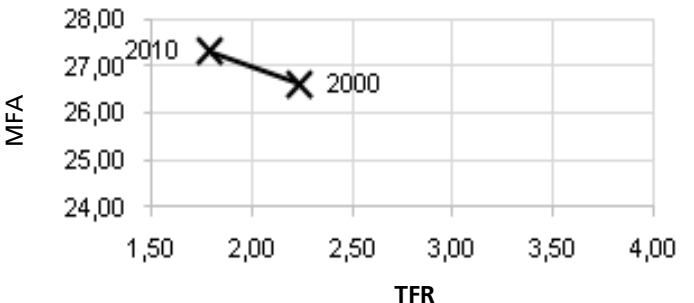

Paraíba

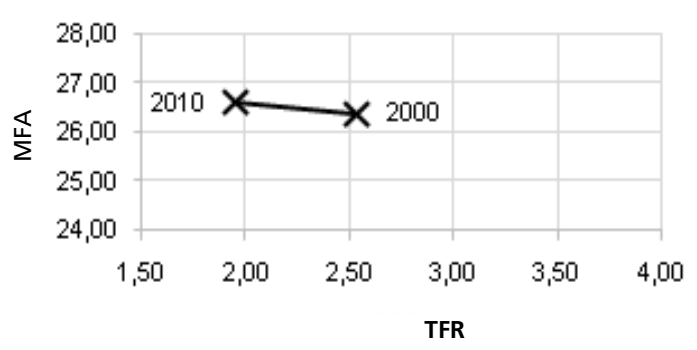

Sergipe

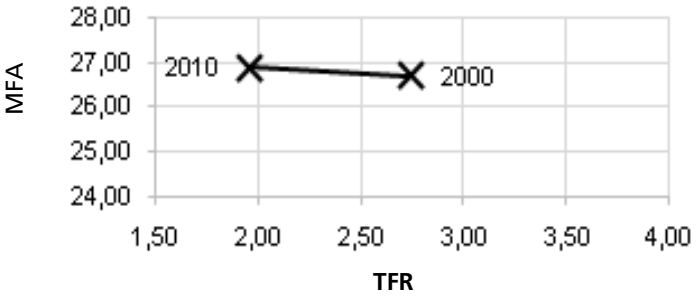

Espírito Santo

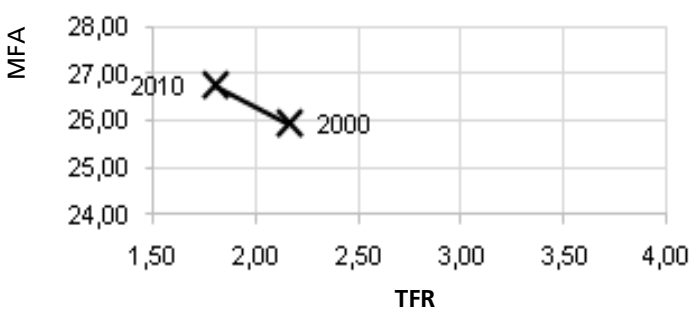


Relation between the Total Fertility Rate and Mean Fertility Age according to the Federation Unit. Brazil, 2000 and 2010.
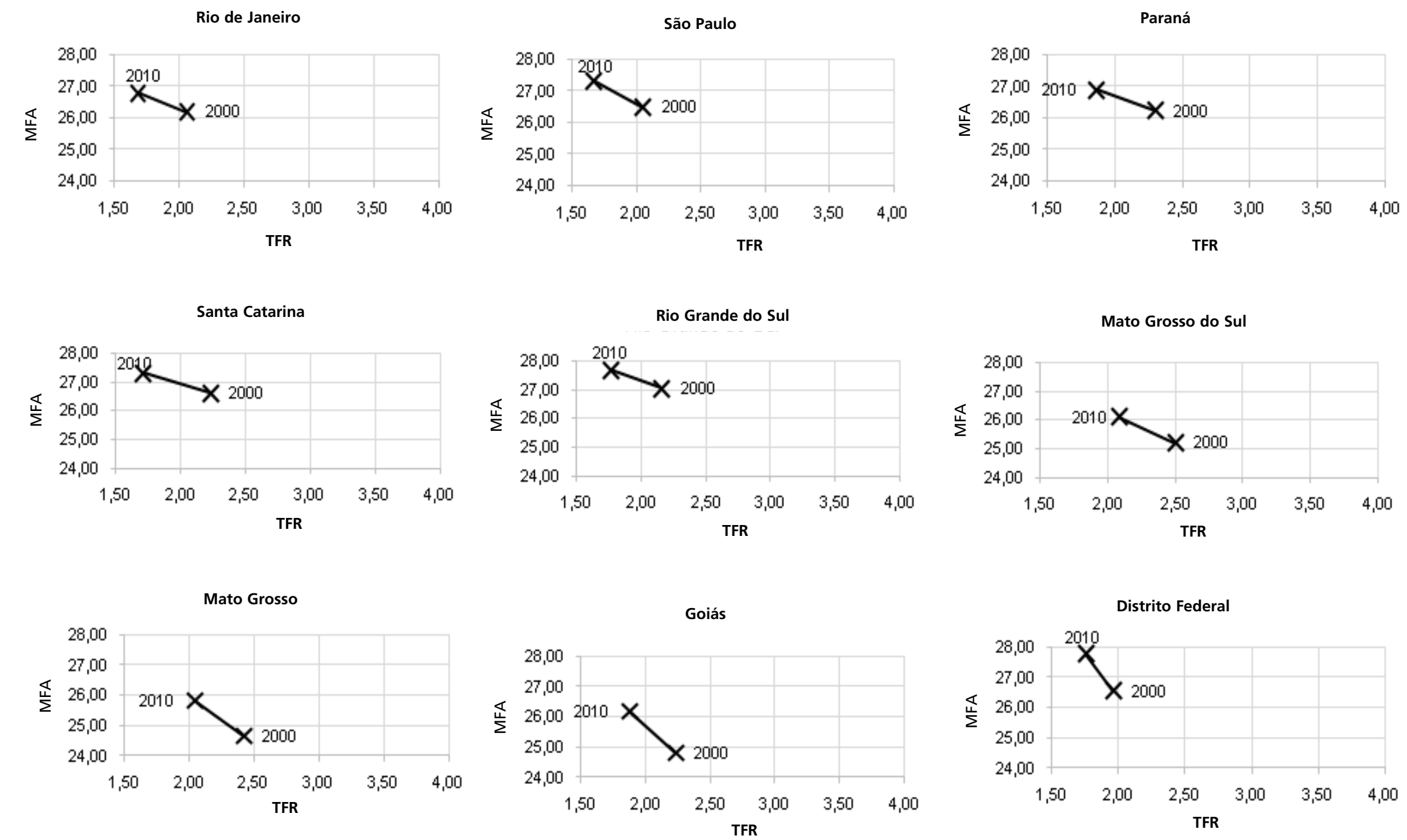

TFR = Total Fertility Rate; MFA = Mean Fertility Age Source: DATASUS, 2018 
Table 2

Correlation analysis between the social and fertility indicators (total fertility rate and mean fertility age). Brazil, 2000 and 2010.

\begin{tabular}{|c|c|c|c|c|c|c|c|}
\hline & & & & 2000 & & & \\
\hline & & 10/40 Ratio & Theil & Gini & HDI & TFR & MFA \\
\hline \multirow[t]{2}{*}{ 10/40 Ratio } & $\rho$ & 1.000 & 0.972 & 0.978 & -0.649 & 0.661 & -0.325 \\
\hline & $p$ valor & & $<0.001$ & $<0.001$ & $<0.001$ & $<0.001$ & 0.098 \\
\hline \multirow[t]{2}{*}{ Theil } & $\rho$ & & 1.000 & 0.973 & -0.603 & 0.568 & $-0,232$ \\
\hline & $p$ valor & & & $<0.001$ & 0.001 & 0.002 & 0.244 \\
\hline \multirow[t]{2}{*}{ Gini } & $\rho$ & & & 1.000 & -0.632 & 0.620 & -0.246 \\
\hline & $p$ valor & & & & $<0.001$ & 0.001 & 0.217 \\
\hline \multirow[t]{2}{*}{ HDI } & $\rho$ & & & & 1.000 & -0.518 & 0.615 \\
\hline & $p$ valor & & & & & 0.006 & 0.001 \\
\hline \multirow[t]{2}{*}{ TFR } & $\rho$ & & & & & 1,000 & -0.610 \\
\hline & $p$ valor & & & & & & 0.001 \\
\hline MFA & $\begin{array}{c}\rho \\
p \text { valor }\end{array}$ & & & & & & 1.000 \\
\hline
\end{tabular}

2010

\begin{tabular}{|c|c|c|c|c|c|c|c|}
\hline & & Razão 10/40 & Theil & Gini & HDI & TFR & MFA \\
\hline \multirow[t]{2}{*}{ 10/40 Ratio } & $\rho$ & 1.000 & & & & & \\
\hline & $p$ valor & & & & & & \\
\hline \multirow[t]{2}{*}{ Theil } & $\rho$ & 0.929 & 1.000 & & & & \\
\hline & $p$ valor & $<0.001$ & & & & & \\
\hline \multirow[t]{2}{*}{ Gini } & $\rho$ & 0.967 & 0.938 & 1.000 & & & \\
\hline & $p$ valor & $<0.001$ & $<0.001$ & & & & \\
\hline \multirow[t]{2}{*}{ HDI } & $\rho$ & -0.771 & -0.650 & -0.786 & 1.000 & & \\
\hline & $p$ valor & $<0.001$ & $<0.001$ & $<0.001$ & & & \\
\hline \multirow[t]{2}{*}{ TFR } & $\rho$ & 0.441 & 0.287 & 0.378 & -0.281 & 1.000 & \\
\hline & $p$ valor & 0.021 & 0.146 & 0.052 & 0.155 & & \\
\hline \multirow[t]{2}{*}{ MFA } & $\rho$ & -0.121 & 0.021 & -0.098 & 0.340 & -0.119 & 1.000 \\
\hline & $p$ valor & 0.546 & 0.917 & 0.628 & 0.083 & 0.555 & \\
\hline
\end{tabular}

$\mathrm{HDI}=$ Human Development Index; TFR = Total Fertility Rate; MFA = Mean Fertility Age.

Source: DATASUS, 2018. 
heterogeneity in the age range of first births. Chile and Uruguay, for example, showed the first stages of postponement of fertility with a lower age at first birth and higher standard deviation than in the developed countries. ${ }^{14}$ This pattern also reflects in the emergence of bimodal curves of the first birth risk by age rates. 14,15

The emergence of this pattern of fertility underreplacement in some Latin American countries since the early 2000s suggests that the region is going through an experience comparable to those lived in Europe, East Asia and North America by some two decades earlier. ${ }^{16}$ However, similarities in fertility levels may hide persistent contrasts in specific patterns of family building parity and at the time of fertility. ${ }^{17}$ For this reason, some analysis at smaller scales, such as the Federative Units, is a strategy that strengthens the theoretical model that considers local development as a direct determinant of fertility. 18

The fertility rate would have started to decline under the effect of female schooling. However, the advancement of education does not happen under a socioeconomic change. The postwar period in Brazil was marked by intense socioeconomic changes and by a process of industrialization that stimulated urbanization and thus facilitated the beginning of universalization of schooling, improving the population's educational levels. 16 It is not known, however, exactly how education affected fertility, outside of Brazil it acts on fertility by postponing the age of marriage and increasing participation in the labor market. In Brazil, the first of these did not happen and the extent of the second is not agreed among specialists. ${ }^{7}$ Thus, it is unlikely that education has changed fertility profiles without the help of simultaneous transformations in socioeconomic organization.

It is important to mention that the scope of theoretical generalization is probably greater in the study of a sustained decrease in fertility than in the study of the onset of fertility decline, and in this sense the influence of changes in the level of gender equity may be more evident at this posterior stage. 19 This means that the high levels of women's participation as individuals in combination with low levels of equity for women in their roles as wives or mothers means that many women end up having fewer children than they aspired to when they were younger. The result for the society is a very low fertility rate. In this way, the reduction of gender inequality in family institutions is a necessary condition for the fertility transition; otherwise, fertility will continue reducing until it reaches the replacement level or falls below.. It should be noted that the improvement of gender relations accelerates the transition process, leading to even lower fertility rates.6,20

Although new empirical findings and theoretical frameworks provide forms to explain the relation between socioeconomic development, gender equity and low fertility, many exceptions require a more comprehensive framework to understand the interaction between these processes. It is important to emphasize that the rhythm and the beginning of the development are two important factors to be considered in the analysis of equity of gender and fertility.

More recently, from new cross-sectional and longitudinal analyses of TFR and HDI, a fundamental shift in the well-established negative relation between fertility and development was observed as the global population entered the twenty-first century. 21 While the development continues to promote fertility decline at low and medium HDI levels, at advanced HDI levels, further development can reverse the declining tendency of fertility. The relationship of development and previously negative fertility has therefore assumed a new pattern, with HDI being positively associated to fertility among highly developed countries. It is assumed that this reversal of fertility resulting from continued economic and social development has the potential to reduce rates of aging the population, thus improving the social and economic problems associated to the emergence and persistence of very low fertility. 22,23 However, two judgments are required. First, the analysis performed in this direction considered only the composite HDI, and not its components (income, longevity and education). Thus, it is necessary to consider whether the relation established between HDI and fertility is reversed for all components. Moreover, it should be considered that the study considered a relatively homogeneous group of countries, so that, within the time interval studied, there was no great variation of the HDI in these countries. It is known that the health benefits for educational level are higher in countries with better human development. Health inequalities attributable to schooling are therefore higher in more developed countries. ${ }^{23}$ This weakening in a negative relation between fertility and economic development in many countries, and a positive relation in some countries has now been documented. ${ }^{24-27}$

Finally, it is important to mention that deep crises or negative phases precipitated in the demographic cycle are almost always followed by "rebounds" or "adjustments" of the demographic system. There is a consensus among researchers and authors that the current low fertility will lead to a gradual recovery.24,28 The decline in fertility, 
possibly leading to an unsustainable population decline, can be corrected, although the adjustment factors in this case are numerous and probably could not be replicated under different historical circumstances. ${ }^{8}$ In this direction, for many years, many countries have insisted on the attempts to find public policies for increasing birth rates. However, as Coleman et al. ${ }^{29}$ pointed out, unlike the factors behind the decline of fertility, the causes of low fertility appear to be beyond the reach of the government policy. This is, as stated earlier, there is a gap between the incentives that generate gender equity in institutions and in the family nuclei. 19 Nevertheless, it is important to think about public policies that fully assist women and their families' health who chose gestation at an older age, including the reorganization of the care network to prepare for this demand with quality. 30 Thereby, we expect to obtain positive results in maintaining the reduction of maternal, infant and fetal mortality rates.

\section{Final considerations}

The revision of the theoretical approaches highlights the necessity to build links among the economic, social, political and cultural determinants and demographic aspects, such as fertility. These factors are mainly related to the urbanization process. Data analysis assisted in the recognition of social inequalities that may cause constraints on the desire to have a child in various population groups. Therefore, it is believed, that this diagnosis contributes to the advance in future scenarios predictions on the fertility rate in the country. These results also serve to diagnose and implement health programs and public policies that can ensure rights and access to reproductive health, especially for the most vulnerable population groups.

The fact that the present study still shows a negative relation for Brazil in 2000, and not significant in 2010 , it shows that the country is at an intermediate stage in the fertility transition when compared to developed countries.

It is clear that the approach to postponing fertility is important. Some questions emerge from this debate: if the postponement of fertility is already a fact, how can the government prepare the Public Health System (SUS) in Brazil to increase the demand for prenatal care for women of older age? Will high risk prenatal care (through secondary care) be able to absorb all the pregnant women with quality or will some changes in the prenatal policy be necessary so that primary care services can see some of these women? Are primary care services prepared to meet pregnant women with this profile? Therefore, reproductive behavior and social policy make important links and they should be included in women's health agendas.

\section{Authors' contributions}

Carreira GB - study design, data extraction, analysis and article writing. Dutra VGP - data analysis and critical review of the final article. Silva JHCM extraction and data analysis. Guimarães RM - study design, data analysis and critical review of the final article. All authors approved the final version of the manuscript.

\section{References}

1. Kreager P. Population theory - A long view. Popul Stud (Camb). 2015; 69 (Suppl. 1): S29-37.

2. Easterlin RA, Crimmins EM. The fertility revolution. In: Easterlin RA e Crimmins EM (eds.). The Fertility Revolution: a supply-demand analysis. Chicago: University of Chicago Press; 1985; 1: 1-11 e 2: 12-33.

3. United Nations. Department of Economic and Social Affairs. Population Division (2014). World Fertility Report 2013: Fertility at the Extremes (United Nations publication). UN, New York; 2014.

4. Blake J. Are Babies Consumer Durables?: A Critique of the Economic Theory of Reproductive Motivation. Popul Stud (Camb). 1968; 22 (1): 5-25.

5. Bryant J. Theories of fertility decline and the evidence from development indicators. PopulDev Rev. 2007; 33: 101-27.

6. Wilson C. Fertility below replacement level. Science. 2004; 304: 207-9.
7. Berquó ES, Cavenaghi SM. Notas sobre os diferenciais educacionais e econômicos da fecundidade no Brasil.Rev Bras EstudPopul. 2014; 31 (2): 471-82.

8. Moultrie TA, Dorrington RE, Hill AG, Hill KH, Timaeus IM, Zaba B(eds). Tools for Demographic Estimation. Paris: International Union for the Scientific Study of Population; 2013.

9. Livi-Bacci M. What we can and cannot learn from the history of world population. Popul Stud (Camb). 2015; 69 (Suppl. 1): S21-8.

10. United Nations. World Population Prospects. The 2012 Revision. New York: United Nations; 2013.

11. Rosero-Bixby L, Castro-Martín T, Martín García T. Is Latin America starting to retreat from early and universal childbearing? DemographicResearch. 2009; 20 (9): 169-94.

12. CEPAL. Panorama Social de América Latina. Santiago de Chile: CEPAL, 2012. 
13. Rodríguez-Vignoli J, Cavenaghi S. Adolescent and Youth Fertility and Social Inequality in Latin America and the Caribbean: What Role Has Education Played? Genus. 2014; 70 (1): 1-25

14. Lima EEC, Myrskylä M. Fertility transition in Brazil: a cohort analysis of fertility anticipation, postponement and recuperation. In: International Union for the Scientific Study of Population-IUSSP.Busan, Korea. Anais. Liège: IUSSP; 2013.

15. Nathan M, Pardo I, Cabella W. Diverging patterns of fertility decline in Uruguay. Demographic Research. 2016; 34: 563-86.

16. Castanheira HC, Kohler HP. It is lower than you think it is: Recent total fertility rates in Brazil and possibly other Latin American countries. PSC Working Paper Series 63 Philadelphia: University of Pennsylvania, Population Studies Center; 2015.

17. Lima EEC, Zeman K, Sobotka T, Nathan M, Castro R. The Emergence of Bimodal Fertility Profiles in Latin America. Popul Dev Rev. 2018; https://doi.org/10.1111/padr.12157. Disponível em: https://onlinelibrary.wiley.com doi/full/10.1111/padr.12157

18. Januzzi PM. Avaliação de programas sociais: conceitos e referenciais de quem a realiza. Estud Aval Educ. 2014; 25(58): 22-42

19. Mc Donald P. Gender equity in theories of fertility transition. Paper presented at the 2000 Annual Meeting of the Population Association of America. Los Angeles, California; 2000

20. Coleman D, Basten S, Billari FC. Population - The long view, Population Studies: A Journal of Demography. 2015; 69 (1): 1-9.
21. Harttgen K, Vollmer S. A reversal in the relationship of human development with fertility?Demography. 2014; 51 (1): 173-84.

22. Myrskylä M, Kohler HP, Billari FC.Advances in development reverse fertility declines. Nature. 2009; 460 (7256):741-3

23. Testa MR. On the positive correlation between education and fertility intentions in Europe: Individual-and countrylevel evidence.Adv Life Course Res. 2014; 21: 28-42.

24. Fox J, Klüsener S, Myrskylä M. Is a Positive Relationship Between Fertility and Economic Development Emerging at the Sub-National Regional Level? Theoretical Considerations and Evidence from Europe. Eur J Popul. 2018; https://doi.org/10.1007/s10680-018-9485-1

25. Anderson T, Kohler HP. Low Fertility, Socioeconomic Development, and Gender Equity Popul Dev Rev. 2015; 41(3): 381-407.

26. Goldstein JR, Cassidy TA. Cohort Model of Fertility Postponement. Demography. 2014; 51 (5): 1797-819.

27. Pantazis A, Clark SJ. A parsimonious characterization of change in global age-specific and total fertility rates. PLoS ONE. 2018; 13 (1): e0190574.

28. Luci-Greulich A, Thévenon O. Does Economic Advancement 'Cause' a Re-increase in Fertility? An Empirical Analysis for OECD Countries (1960-2007). Eur J Popul. 2014; 30 (2): 187-221.

29. Coleman D, Basten S. The Death of the West: An alternative view. Popul Stud (Camb). 2015; 69 (Suppl. 1): 107-18.

30. Cavenaghi SM, Alvez JED. Qualidade das informações sobre fecundidade no Censo Demográfico de 2010. Rev Bras Estud Popul. 2016; 33 (1): 189-205.

Received on May 22, 2018

Final version presented on September 11, 2018

Approved on September 28, 2018 